\title{
Monitoring industrial hydrogenation of soybean oil using self-organizing maps
}

\author{
Jorge Leonardo Sanchez ${ }^{1}$, Sérgio Benedito Gonçalves Pereira ${ }^{2}$, Augusto Tanamati ${ }^{3}$, \\ Ailey Aparecida Coelho Tanamati ${ }^{1}$, Evandro Bona ${ }^{1 *}$ \\ ${ }^{1}$ Post-Graduation Program of Food Technology (PPGTA), Federal University of Technology - Paraná (UTFPR), Via Rosalina Maria dos \\ Santos, 1233, CEP 87301-899, Campo Mourão, Paraná, Brazil, ${ }^{2}$ Chemistry Department, Federal University of Technology - Paraná \\ (UTFPR), Via Rosalina Maria dos Santos, 1233, CEP 87301-899, Campo Mourão, Paraná, Brazil, ${ }^{3} F o o d$ Department, Federal University of \\ Technology - Paraná (UTFPR), Via Rosalina Maria dos Santos, 1233, CEP 87301-899, Campo Mourão, Paraná, Brazil
}

\section{A B S T R A C T}

Monitoring the hydrogenation reaction is crucial to guarantee a product with desired properties. The combination of gas chromatography (GC) with self-organizing maps (SOM) may be an alternative to extract relevant information during the hydrogenation. We analyzed two partially hydrogenated fats produced in an industrial reactor. The quantification of the fatty acids methyl esters and the iodine value (IV) calculation was performed by GC. The SOM was able to cluster the samples according to the IV and reaction time. The weight maps depicted the variation of monounsaturated fatty acids associated with the increase of $18: 1$ and the variation of poly-unsaturated are mainly correlated with 18:2. An increase was observed in saturated fatty acids and trans-fatty acids associated respectively with 18:0 and 18:1 (trans). Besides, it was confirmed that trans-isomers are more stable than the cis-isomers. Therefore, the SOM with GC was an efficient tool for monitoring the hydrogenation process.

Keywords: Process control; Gas chromatography; Artificial neural networks

\section{INTRODUCTION}

Soybeans (Glycine max L.) are the most important source of protein for food and the second greatest source of vegetable oil only behind palm oil (FAO, 2019). Soybeans produce an unsaturated oil rich in linoleic fatty acids $(53 \%)$ and linolenic $(8 \%)$, which are largely responsible for the oxidative instability of the oil (Pereira et al., 2018; Zambiazi, Przybylski, Zambiazi, \& Mendonça, 2007). Thus, it is common for the soybean oil to undergo a process of partial hydrogenation to reduce the amount of unsaturated fatty acids that are sensitive to oxidation and therefore, to improve its shelf life during storage and heating (Karabulut, Kayahan, \& Yaprak, 2003). Partial hydrogenation could be used also to improves biodiesel oxidation stability and cold flow property (Adu-Mensah, Mei, Zuo, Zhang, \& Wang, 2019).

Hydrogenation is the process in which hydrogen is added at unsaturation points of the fatty acids in the presence of a catalyst, which generally is nickel (Dijkstra, 2012).
Catalytic hydrogenation of vegetable oils is a well-accepted and well-established technology in the food industry, with the main interest of increasing the oxidative stability of vegetable oils and producing fats for specific applications (Karabulut et al., 2003). However, an undesirable upshot of the hydrogenation of vegetable oils is the formation of trans isomers whose regular consumption in diets is associated with the risk of cardiovascular disease (Liu, Inbaraj, \& Chen, 2007; Martin, de Oliveira, Visentainer, Matsushita, \& de Souza, 2008). The iodine value (IV) is one of the parameters mostly used for monitoring the progress of the vegetable oils hydrogenation reaction (Dijkstra, 2012; Sanchez et al., 2017). IV represents the relative degrees of unsaturation of the fatty acids and its first introduction in 1884 by German chemist Arthur von Hübl was a breakthrough in the analysis of oils and fats (Li, van de Voort, Sedman, \& Ismail, 1999). The main modification to the method was undertaken later, in 1898, by Wijs, who published a paper in which he used iodine monochloride in glacial acetic acid, nowadays known as Wijs solution (Knothe, 2009). Determining the IV by

\footnotetext{
${ }^{*}$ Corresponding author:

Evandro Bona, Post-Graduation Program of Food Technology (PPGTA), Federal University of Technology - Paraná (UTFPR), Via Rosalina Maria dos Santos, 1233, CEP 87301-899, Campo Mourão, Paraná, Brazil, Tel.: +55 44 3518-1477; E-mail: ebona@utfpr.edu.br

Received: 01 August 2019; $\quad$ Accepted: 12 October 2019
} 
means of the Wijs method is grounded in fixing iodine in the unsaturation of fatty acids and later in quantification by titration with a solution of sodium thiosulphate (AOCS, 2012b). Another reference methodology is determining the IV by way of calculus using the percentage composition of the fatty acids obtained with gas chromatography (AOCS, 2012a). Chromatography and its various techniques, among them gas chromatography (GC), allow for detailed information related to the composition of fatty acids in vegetable oils (Buchgraber, Ulberth, Emons, \& Anklam, 2004). Chromatographic applications make use of information derived from the analytical signals from the instrument, e.g. peak areas, for quantification of fatty acids, classification of vegetable oils and detection of adulterations (Ruiz-Samblás, Marini, Cuadros-Rodríguez, \& González-Casado, 2012).

The oils and fats industry routinely acquires a large amount of data on their products and operational processes with the aim of improving productivity and lessen operational costs. Nonetheless, this broad amount of data obtained from the industrial process requires multivariate statistical techniques in order to extract the most relevant information (Torrecilla, Rojo, Oliet, Domínguez, \& Rodríguez, 2009). In this context, chemometrics must be put in place so as to transform the dataset available in information about the process, which renders a better understanding and better explanation (Pell, Seasholtz, Beebe, \& Koch, 2014). The chemometrics methods were employed for oils and fats in chromatographic data analysis (Bosque-Sendra, CuadrosRodríguez, Ruiz-Samblás, \& de la Mata, 2012; Bucci, Magrí, Magrí, Marini, \& Marini, 2002; Dehghani, Mohammadi, Maghsoudlou, \& Mahoonak, 2012; Marini, Magrì, Bucci, \& Magrì, 2007), physicochemical parameters and infrared spectroscopy (Luna, da Silva, Ferré, \& Boqué, 2013; Zhang et al., 2012). Artificial neural networks (ANN) are one type of non-linear chemometrics methods which may be used in tandem with a broad array of chemical data and process variables (Brodnjak-Vončina, Kodba, \& Novič, 2005; Karaman, Ozturk, Yalcin, Kayacier, \& Sagdic, 2012).

The ANN are mathematical models whose architecture was inspired by biological neural networks (Hanrahan, 2010) and are comprised of simple processing units, which store empirical knowledge by means of a learning process (Bishop, 2006; Haykin, 2008). Self-organizing maps (SOM) or Kohonen Map is a type of ANN with non-supervised learning, which has applications in the identification and classification of vegetable oils (Grošelj, Vračko, Pierna, Baeten, \& Novič, 2008; Marini et al., 2007; Torrecilla et al., 2009). SOM is a method for the analysis of multivariate data widely used for exploratory and clustering problems which may be taken as a non-linear generalization of principal component analysis (Haykin, 2008; Kohonen, 2013a). SOM is formed by a set of units spatially ordered according to some selected topology, normally a twodimensional rectangular or hexagonal grid. Each map unit is represented by a weight vector with the same dimension of the input space (Bona, Silva, Borsato, \& Bassoli, 2012; Link, Guimarães Lemes, Marquetti, dos Santos Scholz, \& Bona, 2014; Melssen, Wehrens, \& Buydens, 2006). SOM compresses the information while maintaining the topological and metric relations most relevant from the data. The technique could be used even for complex tasks, due to its non-linear nature (Kohonen, 2013a). The SOM was already successfully used for classifying soybean according to geographical origin based on mineral content (Cremasco et al., 2016) and wine based on organic acids (Milovanovic et al., 2019).

For partially hydrogenated soybean fat few works make use of artificial neural networks in their chemical characterization (Izadifar, 2005; Pereira et al., 2018; Sanchez et al., 2017) and no papers were found using SOM for monitoring the industrial process of hydrogenation of soybean oil. This paper describes the monitoring of the hydrogenation reaction in an industrial reactor with the use of SOM and GC so that the resulting alterations can be evaluated in the composition of the fatty acids and iodine value.

\section{MATERIALS AND METHODS}

\section{Samples of soybean hydrogenated fat}

The samples of partially hydrogenated soybean oil were obtained from an oils and fat industry, from the city of Campo Mourão (Paraná, Brazil). In total, 113 samples were collected from two fats regularly produced in the industry, generically called A and B. Two batches of product A were evaluated, with a final IV about $60 \mathrm{~g} \mathrm{I}_{2} \cdot 100 \mathrm{~g}_{\text {oil }}{ }^{-1}$ (40 minutes in the reactor) and three batches of product $\mathrm{B}$ with final IV about $80 \mathrm{~g} \mathrm{I}_{2} .100 \mathrm{~g}_{\text {oil }}{ }^{-1}$ (30 minutes in the reactor). The hydrogenation process was carried out in an industrial batch reactor with 22 tons of capacity. The operational parameters were adjusted to the initial temperature of $140^{\circ} \mathrm{C}$ and final temperature of $210^{\circ} \mathrm{C}$, pressure ranging from 1.5 to $3.0 \mathrm{bar}$, stirring rate of $60 \mathrm{~Hz}$, hydrogen flux between 3300 and $3900 \mathrm{~m}^{3} \cdot \mathrm{h}^{-1}$ and addition of 0.02 to $0.07 \%$ of a nickel catalyst. The samples were collected directly from the reactor in each reaction time from time zero and then every 5 minutes until the end of the process. All the samples were stored in borosilicate amber flasks after collection and preserved at a temperature of $-18.0^{\circ} \mathrm{C}$ until the analyses were performed.

\section{Extraction of nickel from the samples}

Since the samples had been collected straight from the hydrogenation reactor, prior to the execution of the fatty 
acids composition analysis using GC, it was necessary to extract the nickel from the samples to avoid damages to the capillary column. Sixty grams of sample was heated in vacuum at $65^{\circ} \mathrm{C}$, and later filtered with a qualitative filter paper (Whatman ${ }^{\circledR}$ No. 42 ) and quickly cooled off at $35^{\circ} \mathrm{C}$. The samples without nickel were stored in amber flasks and preserved at $-18.0^{\circ} \mathrm{C}$.

\section{Fatty acid methyl esters (FAME)}

The FAME was obtained through esterification and transesterification (Hartman \& Lago, 1973; Maia \& Rodrigues-Amaya, 1993). For FAME quantification, methyl tricosanoate (23:0) (No. T9900 Sigma-Aldrich ${ }^{\circledR}$ Co. LLC, Saint Louis - MO, USA) prepared in a concentration of $1.0 \mathrm{mg} \cdot \mathrm{mL}^{-1}$ in isooctane was added as the internal standard. All the solvents employed had a spectroscopic grade and the other reagents had pure analytical grade. The esterification was repeated three times for each sample and FAME obtained were kept in vials of $1.5 \mathrm{~mL}$, kept at $-18.0^{\circ} \mathrm{C}$.

\section{Gas chromatography (GC)}

FAME were analyzed in a gas chromatograph (GC-2010 Plus AF, Shimadzu Co., Kyoto, Japan) with an autosampler (AOC 20i, Shimadzu Co., Kyoto, Japan) equipped with a capillary split/splitless injector and flame ionization detector (FID). The separation was carried out in a capillary column of model BPX-70 (60m x $0.25 \mathrm{~mm}$ d.i. x $0.25 \mu \mathrm{m}$ film thickness, SGE Palo Alto, CA, USA) with a $70 \%$ phase of Cyanopropyl Polysilphenylene-Siloxane optimized for FAME. Fatty acids identification was performed by comparison with the retention time of authentic FAME standards (No. 18919-1AMP Supelco, CRM47885 TraceCERT ${ }^{\circledR}$, Sigma-Aldrich ${ }^{\circledR}$, Bellefonte PA, USA, and FAMQ-005 AccuStandard ${ }^{\circledR}$, New Heaven - Connecticut, USA) prepared in a concentration of $1.0 \mathrm{mg} \cdot \mathrm{mL}^{-1}$ in isooctane. From each sample containing FAME in isooctane, a volume of $1.0 \mu \mathrm{L}$ was injected with a split/splitless ratio of $1: 50$. The temperature of $240^{\circ} \mathrm{C}$ was maintained for the FID detector and $230^{\circ} \mathrm{C}$ for the injector. The initial temperature of the column was at $160^{\circ} \mathrm{C}$ for 2.0 minutes, later raised at a rate of $2^{\circ} \mathrm{C} \cdot \mathrm{min}^{-1}$ until $170^{\circ} \mathrm{C}$ and maintained for 2.0 minutes. Afterward, the temperature was increased to $180^{\circ} \mathrm{C}$ at a rate of $4^{\circ} \mathrm{C}$. $\mathrm{min}^{-1}$, and kept thus for 4.0 minutes and finally to $235^{\circ} \mathrm{C}$ at a rate of $10^{\circ} \mathrm{C} . \mathrm{min}^{-1}$ and maintained during 9.0 minutes. The carrier gas was hydrogen with a flux of $1.24 \mathrm{~mL}$. $\min ^{-1}$ and a linear speed of $35.2 \mathrm{~cm} \cdot \mathrm{s}^{-1}$. The make-up gas was nitrogen in $30.0 \mathrm{~mL} \cdot \mathrm{min}^{-1}$. The FID flame was produced with hydrogen $\left(30.0 \mathrm{~mL} \cdot \mathrm{min}^{-1}\right)$ and synthetic air $\left(300.0 \mathrm{~mL} \cdot \mathrm{min}^{-1}\right)$.

Quantification of the fatty acids was performed with the theoretical correction factors to the differential response of FID and the conversion factors for each FAME
(Visentainer, 2012). The IV ( $\left.\mathrm{g} \mathrm{I}_{2} \cdot 100 \mathrm{~g}_{\text {oil }}{ }^{-1}\right)$ was determined by calculation based on composition in unsaturated fatty acids according to the AOCS Cd 1c-85 method (AOCS, 2012a).

\section{Self-organizing map (SOM)}

In the SOM model, the artificial neurons are associated with knots of a regular grid, generally two-dimensional, Fig. 1A. The learning process begins with the random initialization of the synaptic weights vector $(W j)$ of each neuron. In sequence, three essential steps are developed for feature map formation: competition, cooperation, and synaptic adaptation (Haykin, 2008; Kohonen, 2013a).

At the stage of the competition, each input vector $x$ (the composition of fatty acids and IV of each sample) is compared with the set of model vectors $M_{i}$ through a vector norm; generally, the Euclidean distance is used. The most similar model $\left(M_{c}\right)$ wins the stage of the competition and is denominated the winner neuron (Bona et al., 2012). During the stage of cooperation, the model vectors at the neighborhood of the winning neuron, greatest circle in Fig. 1A, will cooperate to form a specialized region of the SOM in similar patterns of sample $x$ (Kohonen, 2013a). At the stage of adaptation, the weights of the $\mathrm{r}^{\text {th }}$ neuron $\left(w_{\mathrm{r}}\right)$ are altered due to the difference among the values of the sample $x$, Fig. 1B (Ballabio \& Vasighi, 2012). At the end of learning, each sample is associated with its winner neuron, thus forming a topological map that represents the relations of similarity intrinsic to the data. Moreover, it is possible through the weight maps, Fig. 1B, to represent the influence of each variable for sample segmentation (Link et al., 2014; Melssen et al., 2006).

This work employed the two-dimensional SOM algorithm with sequential learning (Link et al., 2014). Two-dimensional maps were created with 10 neurons in each dimension, and the training was conducted until 5,000 epochs in order to ensure the convergence of the mean quantization error (Bona et al., 2012). The initial neighborhood relationship was 4.5 , with an initial learning rate of 0.1 . The SOM algorithm implementation was carried out in MATLAB R2008b (The MathWorks Inc., Natick, USA).

Since random initialization was used, to assess the consistency of the SOM results, multiple initializations were employed using the same procedure described in Bona et al. (2012). It was tested a SOM with a square grid containing from six up to twelve neurons at each dimension. An increase in the map only causes a greater dispersion among the samples, but the neighborhood properties are maintained. Therefore, the tests showed that the map with $10 \times 10$ neurons was sufficient to represent the samples. 


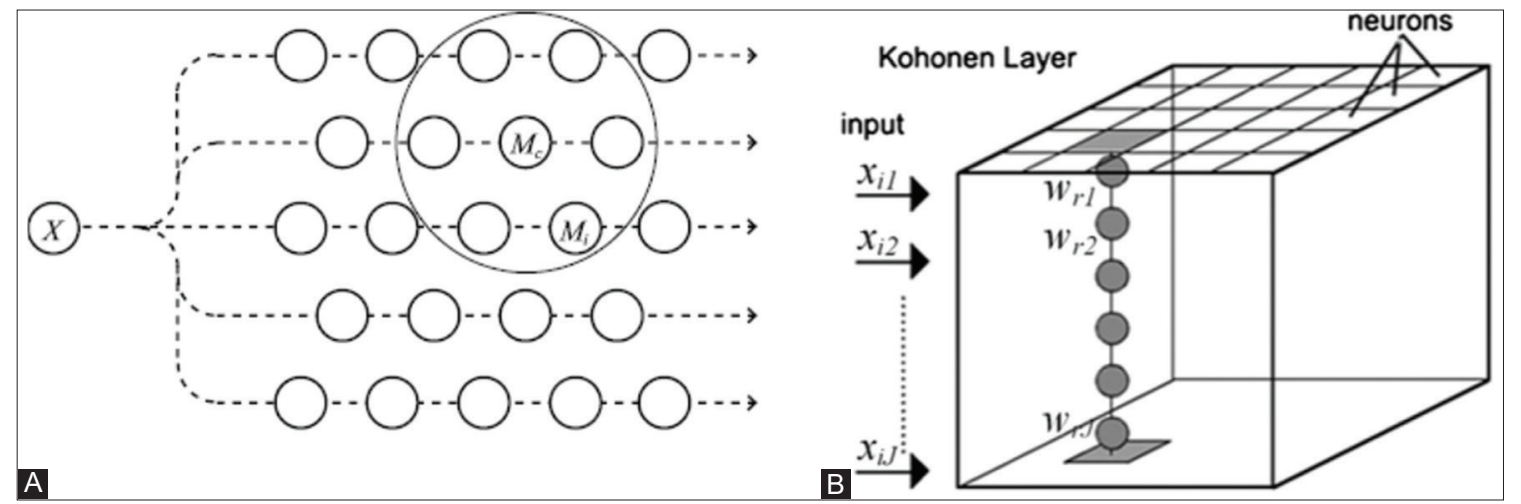

Fig 1. (A) Representation of the knots in a regular two-dimensional grid (Kohonen, 2013b) and (B) the weight layers (Ballabio \& Vasighi, 2012).

\section{RESULTS AND DISCUSSION}

In Tables 1 and 2, it is possible to visualize the main variations in the composition of fatty acids in relation to the time of hydrogenation. As expected for soybean oil, which has high amounts of polyunsaturated fats, an increase of fatty acids 18:0 and 18:1(trans) was observed, and full conversion of the fatty acids 18:2 (cis) and 18:3 (cis) (Cheng, Rau, Dowd, Easson, \& Condon, 2014). Thus, at the end of the process monitored, a partially solid fat was obtained with high amounts of saturated fat, monounsaturated and trans fatty acids. In addition to the hydrogenation, modifications are originated because of a series of other reactions which take place in parallels, such as geometric isomerization and positional isomerization in the unsaturated fatty acids (Jovanovic, 1998; Jovanović, Čupić, Stanković, Rožić, \& Marković, 2000; Šimon, Čelkova, \& Šchmidt, 1991).

Table 1 shows the fatty acids with inexpressive variation during the hydrogenation process. Although the palmitic acid (16:0) presents a greater variability, the ratio standard deviation/mean is similar to the other fatty acids reported in Table 1. The mean values and the behavior observed during the hydrogenation for the fatty acids of Table 1 are the same as described in the literature (Gupta, 2010; O'Brien, 2009).

In Table 2 the mean values obtained are shown, for the iodine value and for the fatty acids with significant variation during the hydrogenation process. Furthermore, the sum of all isomers may be assessed, for saturated fatty acids (SFA), unsaturated fatty acids (UFA), trans fatty acids (TFA), monounsaturated fatty acids (MUFA), and polyunsaturated fatty acids (PUFA) for all sampling times during the hydrogenation reaction. An expressive decrease was observed in IV, on average, from 127.46 to $60.04 \mathrm{~g}$ $\mathrm{I}_{2} .100 \mathrm{~g}_{\text {oil }}{ }^{-1}$, of UFA from 82.59 to $64.94 \%$ and PUFA from 53.31 to $1.82 \%$. In contrast, there was a substantial increase in SFA from 17.24 to $35.09 \%$, of MUFA from
Table 1: Fatty acids with approximately constant concentration during the hydrogenation process

\begin{tabular}{lc}
\hline Fatty acid & Mean Concentration $(\% \mathrm{w} / \mathrm{w})^{\mathrm{a}}$ \\
\hline $14: 0$ & $0.0785 \pm 0.0116$ \\
$16: 0$ & $11.5 \pm 1.39$ \\
$16: 1$ & $0.0742 \pm 0.0100$ \\
$20: 0$ & $0.460 \pm 0.0751$ \\
$20: 1$ & $0.182 \pm 0.0227$ \\
$22: 0$ & $0.516 \pm 0.0796$ \\
$24: 0$ & $0.178 \pm 0.0348$ \\
\hline
\end{tabular}

29.26 to $63.09 \%$, and TFA from 1.38 to $28.45 \%$. The values for 18:2 and 18:3 for time zero are slightly low, on the other hand, TFA should be absent at the begging of the hydrogenation process (Martin, Visentainer, et al., 2008). This variation may be associated with the time required for the operation of the reactor to make the collection of the sample. Probably, some samples associated with zero time may have been gathered in around 3 minutes after entry into the reactor. Thus, it would be a reasonable reduction in the content of 18:2 and 18:3 with an increase in TFA content.

Table 2 shows an increase in standard deviation when the mean is calculated using samples of both products and with various batches. This greater variability between products and even between batches is inherent in the industrial process. The reactor operator may change the conditions of temperature, hydrogen flow and stirring rate during the hydrogenation reaction. The changes in process variables result in different proportions of the fatty acids throughout the reaction.

The IV values and fatty acids proportion of each sample were used as input variables for SOM. Through the multiple initialization procedure, it was observed that the topological properties of the data were preserved and the neighborhood relationships between the samples were the same for all the obtained maps. According to the training graph, which shows the variation of the mean quantization error (Fig. 2), the 5,000 training epochs were sufficient for convergence. 


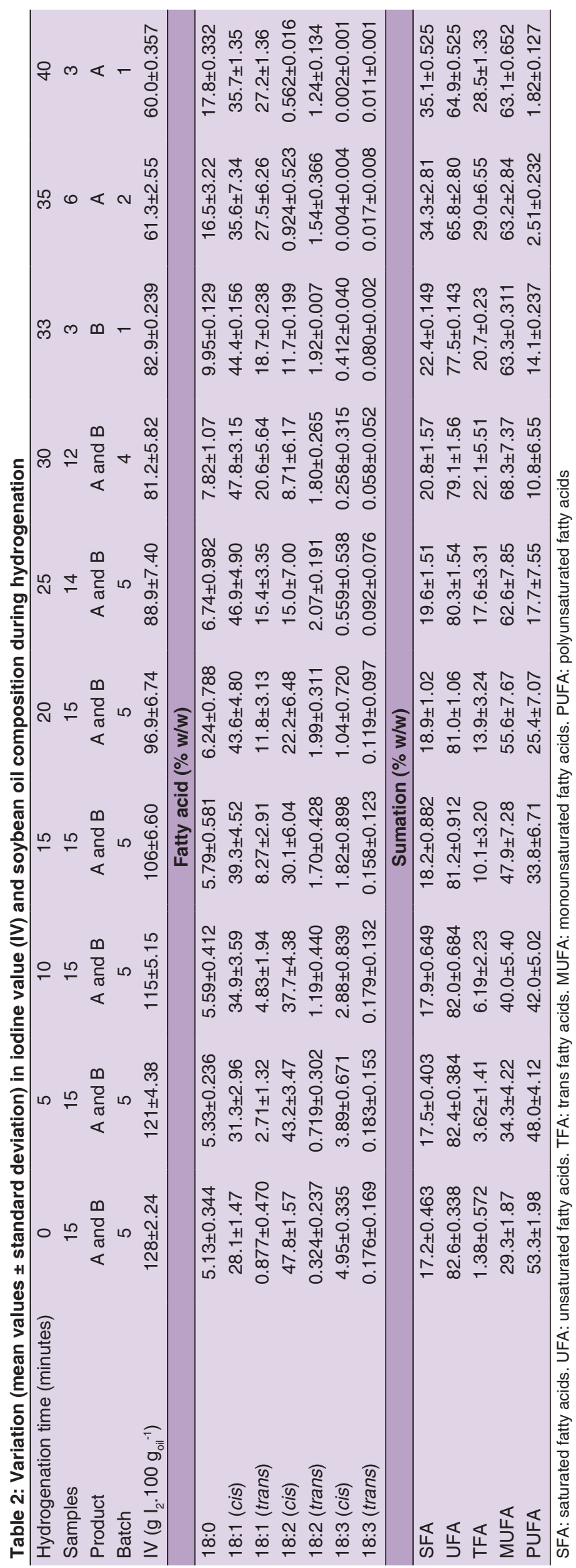

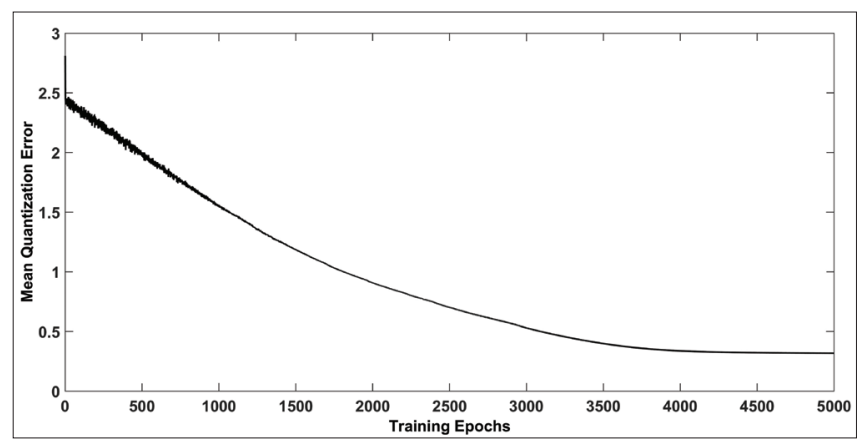

Fig 2. Mean quantization error convergence during the SOM training.

After the training stage, the topological map of the samples and the weight map for each input variable was evaluated. Figs. 3 and 4 illustrate the weight map, overlapped by the topological map, for the variables with the most variation during the hydrogenation. In the topological map, each sample (coded in relation to the sampling time, T00 until $\mathrm{T} 40$, and in relation to the product/batch) is associated with the respective winning neuron, which best represents the sample in SOM. In the weight map, the values observed for the input variables (fatty acids and IV) are indicated by way of color scales within the respective unit. The repetitions which show the same neuron, the name was registered only once in order to facilitate viewing.

In Fig. 3, it is possible to observe that SOM segmented the samples in relation to the hydrogenation reaction time based mainly on IV. In addition, as expected, the IV variable has a positive correlation with the quantity of PUFA, linoleic acid (18:2 cis) and linolenic (C18:3 cis) (Fig. 4). The graphical relation is confirmed by the coefficients of linear correlation between IV and the mentioned variables, which are respectively 0.985 , 0.984 and 0.901 . In contrast, it is also noticed that IV is inversely related to variables TFA and 18:1(trans) with linear correlation coefficients of -0.949 and -0.945 , respectively. These results ascertain that during the hydrogenation process, the reduction in the amounts of unsaturation is followed up by the formation of trans isomers which are thermodynamically more stable (Cunha, 2003; Jovanovic, 1998; Jovanović et al., 2000).

Analyzing the weight map of Figs. 3 and 4, it was observed that the samples up to 10 minutes of reaction have high levels of PUFA and 18:2 (cis). The samples between 15 and 20 minutes have intermediate amounts and, samples of 25 up to 40 minutes have the lowest value to these fatty acids. However, the samples between 25 and 30 minutes have high levels of MUFA and 18:1 (cis), samples between 35 and 40 times, in turn, are highlighted by TFA content, 18:1 (trans) and 18:0. According to the literature data (Gupta, 2010), was expected the complete conversion of $18: 3$ in 


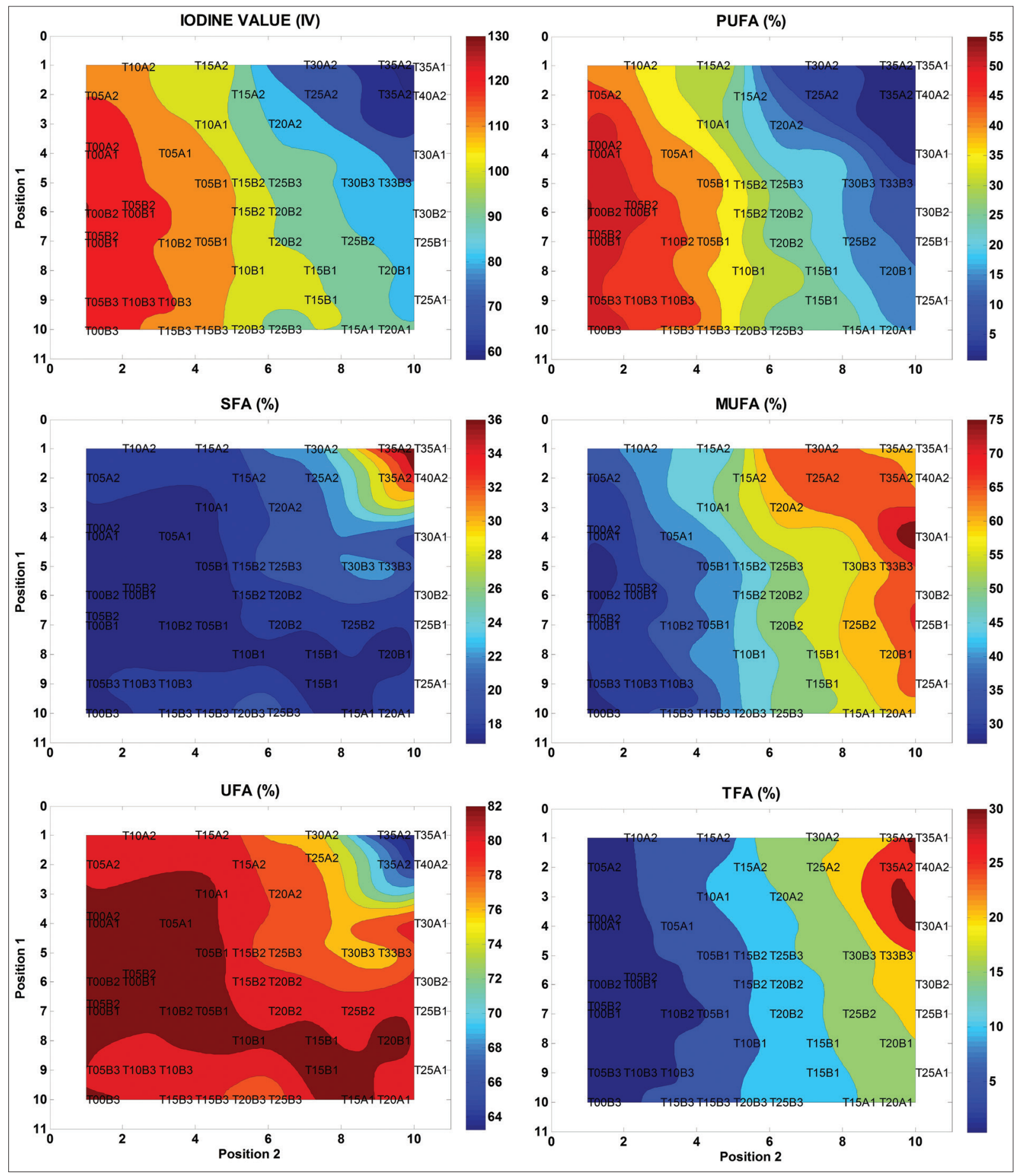

Fig 3. Weight maps overlapped by the topological map for iodine value (IV) and the sum of saturated fatty acids (SFA), unsaturated fatty acids (UFA), trans fatty acids (TFA), monounsaturated fatty acids (MUFA) and polyunsaturated fatty acids (PUFA). The samples are coded in relation to reaction time from T00 to T40 and the product/batch. In the color scale the units are $\mathrm{g} \mathrm{I}_{2} \cdot 100 \mathrm{~g}_{\mathrm{oil}}{ }^{-1}$ for IV, and percentage (w/w) for fatty acids.

IV around $100 \mathrm{~g} \mathrm{I}_{2} \cdot 100 \mathrm{~g}_{\text {oil }}{ }^{-1}(15-20$ minutes $)$ and $18: 2$ in IV around $60 \mathrm{~g} \mathrm{I}_{2} \cdot 100 \mathrm{~g}_{\text {oil }}^{-1}$ (35-40 minutes).

It was observed an increase in 18:1(cis) until the time of 30 minutes (IV $=84 \mathrm{~g} \mathrm{I}_{2} .100 \mathrm{~g}_{\text {oil }}{ }^{-1}$ ) followed by a sharp decrease until 40 minutes of reaction (IV $\left.=60 \mathrm{~g} \mathrm{I}_{2} \cdot 100 \mathrm{~g}_{\text {oil }}{ }^{-1}\right)$. For soybean hydrogenation, it is expected that firstly 18:3 be converted into $18: 2$, and this one then right to
18:1. The increase of $18: 1$ takes place until IV is at about $80 \mathrm{~g} \mathrm{I}_{2} .100 \mathrm{~g}_{\mathrm{oil}}{ }^{-1}$, after this point the conversion of 18:1 to 18:0 occurs, consequently increasing SFA. The TFA increase occurs up to a value of IV nears $60 \mathrm{~g} \mathrm{I}_{2} .100 \mathrm{~g}_{\text {oil }}$ ${ }^{1}$ (40 minutes), after this point begins to occur a decrease due to the conversion of 18:1 (Gupta, 2010). As a condition imposed by the industry for the products analyzed, the hydrogenation reaction was terminated at the time that 
Sanchez, et al.

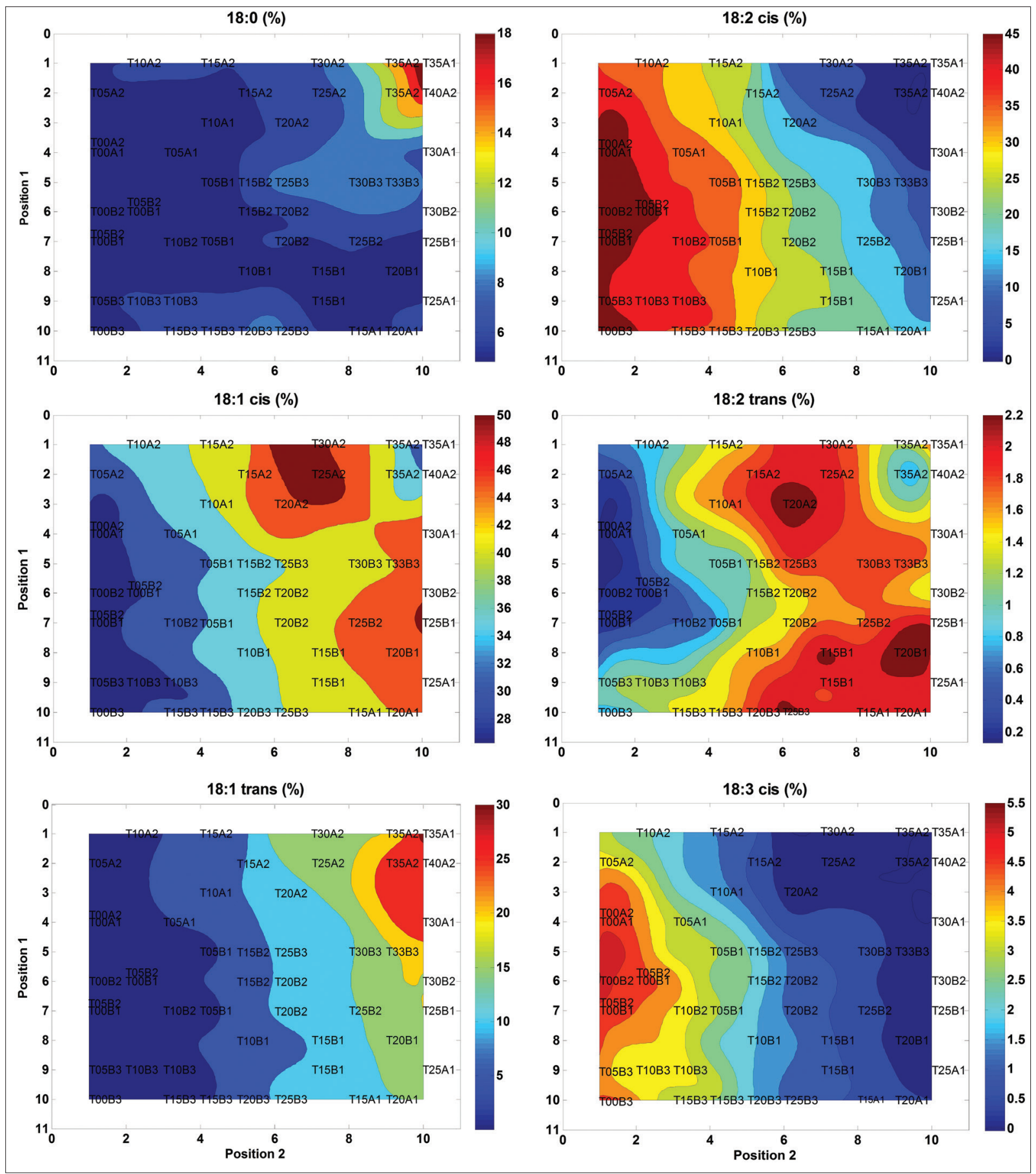

Fig 4. Weight maps overlapped by the topological map for stearic acid (18:0), linolenic (18:3 cis) and the isomers cis and trans of fatty acids 18:1 and 18:2. The samples are coded in relation to the reaction time T00 until T40 and product/batch. In the color scale, the units are in percentage (w/w).

iodine value was around $60 \mathrm{~g} \mathrm{I}_{2} \cdot 100 \mathrm{~g}_{\text {oil }}{ }^{-1}$ for product $\mathrm{A}$ and $80 \mathrm{~g} \mathrm{I}_{2} \cdot 100 \mathrm{~g}_{\text {oil }}{ }^{-1}$ for product B. Therefore, it was not possible to observe within the obtained data the decrease in TFA and the full conversion of 18:1. Jovanović et al. (2000) proposed a mechanism, starting from the linolenic acid, for soybean hydrogenation and estimated the reaction rate constants. In accordance with the values obtained, the conversions of $18: 3$ to $18: 2$ and $18: 2$ to $18: 1$ are quick. However, the conversions among isomers 18:3(cis) to 18:3(trans) and 18:2(cis) to $18: 2$ (trans) show rates of 10 to 100 times lower than the respective saturation reactions. Differently, in the case of $18: 1$, the conversion of $18: 1$ (cis) to $18: 1$ (trans) is 10,000 times quicker than the hydrogenation reaction (18:1 18:0), because the trans isomer is thermodynamically more stable (Cunha, 2003; Jovanović et al., 2000; Karabulut et al., 2003; Liu et al., 2007). This sequence of reactions and trans isomers formation is also observed in the weight map (Figs. 3 and 4). 


\section{CONCLUSIONS}

The hydrogenation process causes significant changes in fatty acid content and the degree of unsaturation of soybean oil which was accompanied by a decrease in iodine value. The application of gas chromatography combined with the self-organizing map allows easy visualization of the transformations that occurred during the industrial manufacturing process of partially hydrogenated soy fat. Moreover, it was possible to confirm the relationship between the fatty acids, the sequence of conversions and the parallel reactions of isomerization. The weight maps of the variables, overlapped by the topological map allow for the identification of the factors that contribute meaningfully to the separation of the samples. Thus, the treatment of data collected routinely by industry using artificial neural networks is presented as a promising alternative for process monitoring, enabling better control over the final product.

\section{CONFLICT OF INTEREST}

The authors have no conflicts of interest to declare.

\section{ACKNOWLEDGMENT}

The authors thank CNPq and CAPES for their financial support.

\section{REFERENCES}

Adu-Mensah, D., D. Mei, L. Zuo, Q. Zhang and J. Wang. 2019. A review on partial hydrogenation of biodiesel and its influence on fuel properties. Fuel. 251: 660-668.

AOCS. 2012a. lodine value (calculated from GLC). In: D. Firestone (Ed.), Official Methods and Recommended Practices of the AOCS. $6^{\text {th }}$ ed. AOCS Press, United States of America, p. 1200.

AOCS. 2012b. Iodine value (Wijs). In: D. Firestone (Ed.), Official Methods and Recommended Practices of the AOCS. $6^{\text {th }}$ ed. AOCS Press, United States of America, p. 1200.

Ballabio, D. and M. Vasighi. 2012. A MATLAB toolbox for Self Organizing Maps and supervised neural network learning strategies. Chemometr. Intell. Lab. Syst. 118: 24-32.

Bishop, C. M. 2006. Pattern Recognition and Machine Learning. $1^{\text {st }}$ ed. Springer, New York.

Bona, E., R. S. S. Silva, D. Borsato and D. G. Bassoli. 2012. Selforganizing maps as a chemometric tool for aromatic pattern recognition of soluble coffee. Acta Sci. Technol. 34(1): 111-119.

Bosque-Sendra, J. M., L. Cuadros-Rodríguez, C. Ruiz-Samblás and A. P. de la Mata. 2012. Combining chromatography and chemometrics for the characterization and authentication of fats and oils from triacylglycerol compositional data a review. Anal. Chim. Acta. 724: 1-11.

Brodnjak-Vončina, D., Z. C. Kodba and M. Novič. 2005. Multivariate data analysis in classification of vegetable oils characterized by the content of fatty acids. Chemometr. Intell. Lab. Syst. 75(1): 31-43.
Bucci, R., A. D. Magrí, A. L. Magrí, D. Marini and F. Marini. 2002 Chemical authentication of extra virgin olive oil varieties by supervised chemometric procedures. J. Agric. Food Chem. 50(3): 413-418.

Buchgraber, M., F. Ulberth, H. Emons and E. Anklam. 2004. Triacylglycerol profiling by using chromatographic techniques. Eur. J. Lipid Sci. Technol. 106(9): 621-648.

Cheng, H. N., M. W. Rau, M. K. Dowd, M. W. Easson and B. D. Condon. 2014. Comparison of soybean and cottonseed oils upon hydrogenation with nickel, palladium and platinum catalysts. J. Am. Oil Chem. Soc. 91(8): 1461-1469.

Cremasco, H., D. Borsato, K. G. Angilelli, O. F. Galão, E. Bona and M. F. Valle. 2016. Application of self-organising maps towards segmentation of soybean samples by determination of inorganic compounds content. J. Sci. Food Agric. 96(1): 306-310.

Cunha, S. 2003. Estabilidade relativa de alcenos: Análise dos critérios encontrados nos livros textos de graduação e uma proposta de explicação operacional para alcenos dissubstituídos. Quím. Nova. 26(6): 948-951.

Dehghani, A. A., Z. B. Mohammadi, Y. Maghsoudlou and A. S. Mahoonak. 2012. Intelligent Estimation of the canola oil stability using artificial neural networks. Food Bioproc. Technol. 5(2): 533-540

Dijkstra, A. J. 2012. Kinetics and mechanism of the hydrogenation process the state of the art. Eur. J. Lipid Sci. Technol. 114(9): 985-998.

FAO. 2019. Food and Agriculture Organization of the United Nations FAOSTAT. Available from: http://www.faostat3.fao.org/home/E. [Last accessed on 2019 May 25].

Grošelj, N., M. Vračko, J. A. F. Pierna, V. Baeten and M. Novič. 2008. The use of FT-MIR spectroscopy and counter-propagation artificial neural networks for tracing the adulteration of olive oil. Acta Chim. Slov. 55(4): 935-941. Available from: http://www. acta.chem-soc.si/55/55-4-935.pdf.

Gupta, M. K. 2010. Practical Guide to Vegetable Oil Processing. $1^{\text {st }}$ ed. Available from: http://www.books.google.com.br/ books? $i d=q e c o G Q A A C A A J$.

Hanrahan, G. 2010. Computational neural networks driving complex analytical problem solving. Anal. Chem. 82(11): 4307-4313.

Hartman, L. and R. C. A. Lago. 1973. Rapid determination of fatty acid methyl esthers from lipids. Lab. Pract. 22: 475-477.

Haykin, S. 2008. Neural Networks and Learning Machines. $3^{\text {rd }}$ ed. Prentice Hall, New York.

Izadifar, M. 2005. Neural network modeling of trans isomer formation and unsaturated fatty acid changes during vegetable oil hydrogenation. J. Food Eng. 66(2): 227-232.

Jovanovic, D. 1998. Nickel hydrogenation catalyst for tallow hydrogenation and for the selective hydrogenation of sunflower seed oil and soybean oil. Catal. Today. 43(1-2): 21-8.

Jovanović, D., Z. Čupić, M. Stanković, L. Rožić and B. Marković. 2000. The influence of the isomerization reactions on the soybean oil hydrogenation process. J. Mol. Catal. A Chem. 159(2): 353-357.

Karabulut, I., M. Kayahan and S. Yaprak. 2003. Determination of changes in some physical and chemical properties of soybean oil during hydrogenation. Food Chem. 81(3): 453-456.

Karaman, S., I. Ozturk, H. Yalcin, A. Kayacier and O. Sagdic. 2012. Comparison of adaptive neuro-fuzzy inference system and artificial neural networks for estimation of oxidation parameters of sunflower oil added with some natural byproduct extracts. J. Sci. Food. Agric. 92(1): 49-58.

Knothe, G. 2009. Arthur von Hübl and the lodine Value. The AOCS Lipid Library. Available from: http://www.lipidlibrary.aocs.org/ 
history/Hubl/index.htm. [Last accessed on 2015 Jul 17].

Kohonen, T. 2013a. Essentials of the self-organizing map. Neural Netw. 37: 52-65.

Kohonen, T. 2013b. Essentials of the self-organizing map. Neural Netw. 37: 52-65.

Li, H., F. R. van de Voort, J. Sedman and A. A. Ismail. 1999. Rapid determination of cis and trans content, iodine value, and saponification number of edible oils by fourier transform nearinfrared spectroscopy. J. Am. Oil Chem. Soc. 76(4): 491-497.

Link, J. V., A. L. G. Lemes, I. Marquetti, M. B. dos Santos Scholz and E. Bona. 2014. Geographical and genotypic segmentation of arabica coffee using self-organizing maps. Food Res. Int. 59: 1-7.

Liu, W. H., B. S. Inbaraj and B. H. Chen. 2007. Analysis and formation of trans fatty acids in hydrogenated soybean oil during heating. Food Chem. 104(4): 1740-1749.

Luna, A. S., A. P. da Silva, J. Ferré and R. Boqué. 2013. Classification of edible oils and modeling of their physico-chemical properties by chemometric methods using mid-IR spectroscopy. Spectrochim. Acta A Mol. Biomol. Spectrosc. 100: 109-114.

Maia, E. L. and D. Rodrigues-Amaya. 1993. Avaliação de um método simples e econômico para metilação de ácidos graxos com lipídios de diversas espécies de peixes. Rev. Inst. Adolfo Lutz. 53(1): 27-35.

Marini, F., A. L. Magrì, R. Bucci and A. D. Magrì. 2007. Use of different artificial neural networks to resolve binary blends of monocultivar Italian olive oils. Anal. Chim. Acta. 599(2): 232-240.

Martin, C. A., C. C. de Oliveira, J. V. Visentainer, M. Matsushita and N. E. de Souza. 2008. Optimization of the selectivity of a cyanopropyl stationary phase for the gas chromatographic analysis of trans fatty acids. J. Chromatogr. A. 1194(1): 111-117.

Martin, C. A., J. V. Visentainer, A. N. Oliveira, C. C. Oliveira, M. Matsushita and N. E. Souza. 2008. Fatty acid contents of Brazilian soybean oils with emphasis on trans fatty acids. J. Braz. Chem. Soc. 19(1): 117-122.

Melssen, W., R. Wehrens and L. Buydens. 2006. Supervised Kohonen networks for classification problems. Chemometr. Intell. Lab. Syst. 83(2): 99-113.

Milovanovic, M., J. Žeravík, M. Obořil, M. Pelcová, K. Lacina, U. Cakar and P. Skládal. 2019. A novel method for classification of wine based on organic acids. Food Chem. 284: 296-302.

O'Brien, R. D. 2009. Fats and Oils: Formulating and Processing for Applications. $3^{\text {rd }}$ ed. CRC Press, Boca Raton, Florida. Available from: http://www.openisbn.com/isbn/1420061666.

Pell, R. J., M. B. Seasholtz, K. R. Beebe and M. V. Koch. 2014. Process analytical chemistry and chemometrics, Bruce Kowalski's legacy at the dow chemical company. J. Chemometr. 28(5): 321-331.

Pereira, J. M. G., J. L. Sanchez, P. C. de Lima, G. Possebon, A. Tanamati, A. A. C. Tanamati and E. Bona. 2018. Industrial hydrogenation process monitoring using ultra-compact nearinfrared spectrometer and chemometrics. Food Anal. Methods. 11(1): 188-200.

Ruiz-Samblás, C., F. Marini, L. Cuadros-Rodríguez and A. GonzálezCasado. 2012. Quantification of blending of olive oils and edible vegetable oils by triacylglycerol fingerprint gas chromatography and chemometric tools. J. Chromatogr. B. 910: 71-77.

Sanchez, J. L., S. B. G. Pereira, P. C. de Lima, G. Possebon, A. Tanamati, R. J. Poppi and E. Bona. 2017. Mid-infrared spectroscopy and support vector machines applied to control the hydrogenation process of soybean oil. Eur. Food Res. Technol. 243(8): 1447-1457.

Šimon, P., A. Čelkova and S. Šchmidt. 1991. A simplified HoriutiPolanyi scheme for the hydrogenation of triacylglycerols. J. Am. Oil Chem. Soc. 68(2): 74-78.

Torrecilla, J. S., E. Rojo, M. Oliet, J. C. Domínguez and F. Rodríguez. 2009. Self-organizing maps and learning vector quantization networks as tools to identify vegetable oils. J. Agric. Food Chem. 57(7): 2763-2769.

Visentainer, J. V. 2012. Aspectos analíticos da resposta do detector de ionização em chama para ésteres de ácidos graxos em biodiesel e alimentos. Quím. Nova. 35(2): 274-279.

Zambiazi, R. C., R. Przybylski, M. W. Zambiazi and C. B. Mendonça. 2007. Fatty acid composition of vegetable oils and fats. Bol. Cent. Pesqui. Processamento Aliment. 25(1): 111-120.

Zhang, Q., C. Liu, Z. Sun, X. Hu, Q. Shen and J. Wu. 2012 Authentication of edible vegetable oils adulterated with used frying oil by fourier transform infrared spectroscopy. Food Chem. 132(3): 1607-1613. 